\title{
Plant Availability of Phosphorus in Five Gasification Biochars
}

\author{
Xiaoxi Li' ${ }^{1 \dagger}$, Gitte H. Rubæk', Dorette S. Müller-Stöver ${ }^{2}$, Tobias P. Thomsen ${ }^{3}$, \\ Jesper Ahrenfeldt ${ }^{3}$ and Peter Sørensen ${ }^{1 *}$ \\ 'Department of Agroecology, Aarhus University, Tjele, Denmark, ${ }^{2}$ Department of Plant and Environmental Sciences, \\ University of Copenhagen, Frederiksberg, Denmark, ${ }^{3}$ Department of Chemical and Biochemical Engineering, Technical \\ University of Denmark, Roskilde, Denmark
}

\section{OPEN ACCESS}

Edited by:

Maria Cruz Garcia Gonzalez, Instituto Tecnológico Agrario de Castilla y León, Spain

Reviewed by: Eliana Lanfranca Tassi, Istituto per lo Studio degli Ecosistemi (CNR), Italy Francisco Jesus

Fernandez Morales, Universidad de

Castilla-La Mancha, Spain

${ }^{*}$ Correspondence: Peter Sørensen ps@agro.au.dk

${ }^{+}$Present address: Xiaoxi Li, Agriculture and Food, CSIRO, Canberra, ACT, Australia

Specialty section: This article was submitted to Waste Management in Agroecosystems, a section of the journal Frontiers in Sustainable Food Systems

Received: 25 October 2017 Accepted: 07 December 2017 Published: 22 December 2017

Citation:

Li X, Rubæk GH, Müller-Stöver DS,

Thomsen TP, Ahrenfeldt $J$ and Sørensen P (2017) Plant Availability of Phosphorus in Five Gasification Biochars. Front. Sustain. Food Syst. 1:2. doi: 10.3389/fsufs.2017.00002
The innovation and expansion in the bioenergy sector produce increased amounts of solid residues, e.g., ashes and biochars, which may derive from more diverse origins of biomass. Recycling of nutrients like phosphorus $(P)$ in such residues to agricultural soils contributes to sustainability in both energy and agriculture systems. In this study, the $P$ availability was tested in five gasification biochars (GBs) produced via a novel low-temperature $\left(<750^{\circ} \mathrm{C}\right)$ gasification technology. The feedstocks used were wheat straw (STR), shea nut shells (NUT), poultry manure (POUL), and two types of sewage sludge mixed with wheat straw (SSA and SSB). A 16-week laboratory incubation study of the materials was conducted with three contrasting soils and resin-extractable $\mathrm{P}$ (available $\mathrm{P}$ ) and $\mathrm{pH}$ were monitored. Another mini-plot experiment was done to examine the effects of GBs on spring barley on a loamy sand soil. Neither barley yield nor $P$ uptake showed significant increase after application of the GBs or a mineral $P$ fertiliser, indicating non-limiting $\mathrm{P}$ status in this soil and non-adverse effect on the crop growth. During the incubation, all GBs increased soil pH markedly, especially in the STR- and NUT-amended soils and in acid soils. Of the P applied in STR, NUT, and POUL 21-29\% was recovered as resin-extractable $P$ in the two acid soils after incubation, while in the alkaline soil the recovery from STR (49\%) almost matched that from triple superphosphate (52\%). Recoveries from SSA and SSB were similarly low $(<14 \%)$. A significant positive relationship was identified between the resin-extractable $P$ and the resulting $\mathrm{pH}$ in soils amended with some GBs with low $P$ contents. These results revealed varying $P$ availability of low-temperature GBs, which depends on the feedstock type and $\mathrm{pH}$ level in the soil, and it also showed a varying ability of GBs to substitute mineral P fertilisers.

Keywords: gasification biochar, low temperature circulating fluidised bed, phosphorus availability, spring barley, soil pH

\section{INTRODUCTION}

Combustion and gasification are the two primary forms of using biomass for power and heat generation. Appropriate reuse of the residue after gasification, a solid mixture of ash and char termed gasification biochar (GB), is crucial for sustainability of the energy system (Pan and Eberhardt, 2011; Ahrenfeldt et al., 2013) and a circular economy. Many elements are concentrated in the GB, especially essential non-renewable and irreplaceable nutrients for crop production such as phosphorus 
(P), which need to be properly recycled (Mozaffari et al., 2002; Kuligowski et al., 2010; Müller-Stöver et al., 2012). Direct application of GB to agricultural soils is a low-cost strategy of nutrient recycling, but only if the nutrients in the GBs are available to and get utilised by the plants. The plant availability of P in GBs applied to agricultural soils remains uncertain.

Most studies on soil application of biochars have been conducted with biochars originating from pyrolysis (PB), i.e., operated in the absence of $\mathrm{O}_{2}$ at low temperatures (e.g., $200-700^{\circ} \mathrm{C}$, Spokas et al., 2012; Crane-Droesch et al., 2013). To achieve a higher energy efficiency, gasification is operated in the presence of low $\mathrm{O}_{2}$ concentrations at temperatures of $c a .700-1,000^{\circ} \mathrm{C}$. For both $\mathrm{PB}$ and GB, the operational temperature and the type of feedstock are important factors in determining their subsequent physical and chemical properties (Pan and Eberhardt, 2011; Trippe et al., 2015). With greater demand for biomass in the energy sector, it is desirable to use a broad variety of feedstocks. However, biomasses with high contents of low melting point ashes, such as straw, manure, and sewage sludge, often cause problems related to ash melt during combustion or gasification at high temperatures, e.g., $>800^{\circ} \mathrm{C}$ (Thomsen et al., 2015). Such problems can be largely avoided with the low-temperature circulating fluidised bed (LT-CFB) gasifier, where the maximum process temperature does not exceed $750^{\circ} \mathrm{C}$ (Ahrenfeldt et al., 2013; Hansen et al., 2015).

There is a risk of self-ignition of some freshly produced GB residues if they come into contact with atmospheric oxygen because of the potentially large amount of unburned $\mathrm{C}$ and the high temperature. Adding water is a simple strategy to avoid this, which additionally reduces dust issues during the postgasification processing of the biochars. During such wetting and subsequent drying processes before field application, soluble compounds may dissolve and reprecipitate as new compounds. It is unknown how this can affect the availability of $\mathrm{P}$ afterwards.

Only a few studies have examined the P availability of GBs from different origins. Pan and Eberhardt (2011) evaluated the $\mathrm{P}$ availability in ashes from gasification and combustion of wood chips using sequential chemical extraction. They showed that the majority of the $\mathrm{P}$ in gasification ash was in the potentially bioavailable fraction. Some studies found that GBs from wheat straw and alfalfa stems were able to increase soil Olsen P levels, which was not the case for GBs from other types of feedstocks such as citrus peels (Mozaffari et al., 2002; Müller-Stöver et al., 2012). Another study on biochars from pig and poultry manure gasification reported that the initial $\mathrm{P}$ availability for spring barley was lower than that after the application of a commercial P fertiliser, but that in the longer term the P availability was similar for GB and the commercial fertiliser (Kuligowski et al., 2010).

In a meta-analysis of 40 studies with PBs, potential effects of biochar on crop yield appeared to be dependent on soil properties (Crane-Droesch et al., 2013). Soil properties also influence the $P$ availability to crops in biochar-amended soils (Zhai et al., 2015). The complex soil processes that control $\mathrm{P}$ availability include adsorption-desorption of phosphate on the surfaces of iron and aluminium oxides, organic matter, and other clay minerals and/ or precipitation as various calcium phosphates, and soil $\mathrm{pH}$ plays a crucial role for all these processes (Haynes, 1982; Holford, 1997; Weng et al., 2011). Adsorption-desorption of $\mathrm{P}$ and thus the availability of $\mathrm{P}$ has previously been investigated in $\mathrm{PB}$-amended soils (e.g., Morales et al., 2013; Xu et al., 2014). Variable, even conflicting, responses of $\mathrm{P}$ availability were reported depending on biochar and soil types, which were mainly attributed to the alterations caused by biochar addition to the aforementioned complex soil processes. There is little information about the $\mathrm{P}$ availability as affected by addition of GB to different soil types.

The objective of this work was to evaluate the $\mathrm{P}$ availability in five GBs produced by LT-CFB gasification of wheat straw, shea nut residues, poultry manure, and two types of sewage sludge-wheat straw mixtures. The study comprised one 16-week laboratory incubation experiment with three soil types with contrasting $\mathrm{pH}$ and clay contents, and one mini-plot field experiment on a loamy sand soil with spring barley as the test plant. The hypotheses were that: the P availability in GBs (1) varies among different types of feedstock and soil to which they are applied; (2) is lower than that of mineral P fertilisers but will contribute to crop P uptake and yield; and (3) is affected by drying and wetting of the material during storage.

\section{MATERIALS AND METHODS}

\section{Gasification Biochars}

The GBs originated from various types of biomass and were produced via LT-CFB gasifiers at $700-750^{\circ} \mathrm{C}$ in three pilot or demonstration gasification units in Denmark. The biomass feedstocks included wheat straw (STR and STR1-4), shea nut shells (NUT), poultry manure (POUL), and two mixtures of dry sludge pellets and wheat straw (SSA and SSB). Two different batches of straw were used to produce STR and STR1-4 but under the same conditions. Selected properties and application rates of the GBs in the incubation experiment are presented in Table 1. All materials were in a very fine powder form. The SSA, SSB, and POUL biochars were applied in dry form, while the STR and NUT contained 57 and 54\% water, respectively. More detailed descriptions of the GBs applied in this study can be found in Li et al. (2017). The gasification process was described in detail in Ahrenfeldt et al. (2013) and Thomsen et al. (2015).

\section{Soil for the Incubation Experiment}

Three Danish soils with contrasting clay contents and $\mathrm{pH}$ (Table 2) were used in an incubation experiment to study the $\mathrm{P}$ availability after application of GBs. The soils were all sampled from the plough layer of arable fields. The Aarup soil contained $17 \%$ clay and had a $\mathrm{pH}\left(\mathrm{H}_{2} \mathrm{O}\right)$ of 5.8. The Jyndevad $\mathrm{E}$ and Jyndevad P soils were from different treatments of a long-term experiment that explores the effects of liming and $\mathrm{P}$ fertilisation at St. Jyndevad Experimental Station in southern Denmark (Rubæk, 2008). The Jyndevad E soil was from plots that had not received P fertiliser since 1942, but lime every 6-9 years to achieve a soil pH of 5.4 (low lime). The Jyndevad P soil was from plots that had received triple superphosphate (TSP) at $15.6 \mathrm{~kg} \mathrm{P} \mathrm{ha}^{-1} \mathrm{year}^{-1}$ and lime regularly (target pH 6.7, high lime) (Rubæk, 2008). The soil at Jyndevad is a coarse sand soil with $3.2 \%$ clay and has been continuously cultivated with spring barley for many decades. The Jyndevad soils were sampled about 10 months after a liming event 
TABLE 1 | Selected properties and application rates of gasification biochars (GBs) or mineral fertilisers in the incubation experiment (Li et al., 2017).

\begin{tabular}{|c|c|c|c|c|c|c|c|c|c|c|c|c|c|}
\hline \multirow[t]{3}{*}{ Treatment $^{\mathrm{a}}$} & \multicolumn{7}{|c|}{ Concentration } & \multirow{3}{*}{$\begin{array}{c}\text { WSP }^{b} \\
\%\end{array}$} & \multicolumn{3}{|c|}{ Molar ratio } & \multicolumn{2}{|c|}{ Application rate } \\
\hline & C & $\mathbf{N}$ & $\mathbf{P}$ & $\mathbf{K}$ & $\mathrm{Ca}$ & $\mathbf{M g}$ & $\mathrm{Fe}$ & & Ca:P & $M g: P$ & Fe:P & Fertiliser/GB & $\mathbf{P}$ \\
\hline & \multicolumn{7}{|c|}{$\mathrm{g} \mathrm{kg}^{-1} \mathrm{DM}$} & & & & & & \\
\hline Con & - & - & - & - & - & - & - & - & - & - & - & 0 & 0 \\
\hline ConK & NA & NA & 0 & 524 & NA & NA & NA & 0 & - & - & - & 1.9 & 0 \\
\hline ConP & NA & NA & 216.6 & NA & NA & NA & NA & 90.2 & - & - & - & 0.6 & 138.5 \\
\hline STR & 372 & 3.0 & 4.0 & 55 & 27 & 5.7 & 2.0 & 8.61 & 5.3 & 1.8 & 0.3 & 17.3 & 69.3 \\
\hline NUT & 594 & 12.9 & 8.7 & 78 & 15 & 10.4 & 3.5 & 22.6 & 1.4 & 1.5 & 0.2 & 15.8 & 138.5 \\
\hline POUL & 93 & 8.3 & 57.1 & 91 & 156 & 16.2 & 8.6 & 0.06 & 2.1 & 0.4 & 0.1 & 2.4 & 138.5 \\
\hline SSA & 274 & 7.8 & 26.0 & 51 & 52 & 8.5 & 23.5 & 0.51 & 1.6 & 0.4 & 0.5 & 5.3 & 138.5 \\
\hline SSB & 222 & 3.1 & 26.0 & 84 & 53 & 8.4 & 30.8 & 3.92 & 1.6 & 0.4 & 0.7 & 5.3 & 138.5 \\
\hline
\end{tabular}

${ }^{a}$ Con, control without any amendment; ConK, reference treatment amended with potassium chloride (KCl); ConP, reference treatment amended with triple superphosphate (TSP); STR, straw GB; NUT, shea nut shell GB; POUL, poultry manure GB; SSA, straw-sewage sludge A GB; SSB, straw-sewage sludge B GB. All GBs were produced at ca. $730^{\circ} \mathrm{C}$. ${ }^{b}$ Fraction of water-soluble $P$ to total $P(\%)$.

TABLE 2 | Selected properties of the soils used for the incubation and field mini-plot experiments.

\begin{tabular}{|c|c|c|c|c|c|}
\hline \multirow[t]{2}{*}{ Soil } & \multirow[t]{2}{*}{ Unit } & \multicolumn{3}{|c|}{ Incubation } & \multirow{2}{*}{$\begin{array}{c}\text { Field } \\
\text { mini-plot }^{\mathrm{a}}{ }^{\mathrm{m}} \\
\text { Foulum }\end{array}$} \\
\hline & & Aarup & Jyndevad E & Jyndevad P & \\
\hline Texture & & $\begin{array}{l}\text { Loam } \\
\text { soil }\end{array}$ & $\begin{array}{l}\text { Coarse } \\
\text { sand soil }\end{array}$ & $\begin{array}{l}\text { Coarse } \\
\text { sand soil }\end{array}$ & $\begin{array}{l}\text { Loamy } \\
\text { sand soil }\end{array}$ \\
\hline Clay $(<2 \mu \mathrm{m})$ & $\%$ & 17.0 & 3.2 & 3.2 & 8.6 \\
\hline Silt (2-20 um) & $\%$ & 22.0 & 2.8 & 3.3 & 12.0 \\
\hline $\begin{array}{l}\text { Coarse silt } \\
(20-63 \mu \mathrm{m})\end{array}$ & $\%$ & 23.0 & 2.4 & 2.6 & - \\
\hline $\begin{array}{l}\text { Fine sand } \\
(63-200 \mu \mathrm{m})\end{array}$ & $\%$ & 19.0 & 14.1 & 15.7 & $46.6^{b}$ \\
\hline $\begin{array}{l}\text { Coarse sand } \\
(200-2,000 \mu \mathrm{m})\end{array}$ & $\%$ & 15.2 & 75.5 & 73.4 & 32.8 \\
\hline Total C & $\%$ & 1.9 & 1.2 & 1.1 & 1.8 \\
\hline Total N & $\%$ & 0.2 & 0.1 & 0.1 & 0.2 \\
\hline Olsen P & $\mathrm{mg} \mathrm{kg}^{-1}$ & 14.4 & 19.6 & 25.3 & 24.0 \\
\hline $\mathrm{WSP}^{\mathrm{c}}$ & $\mathrm{mg} \mathrm{kg}^{-1}$ & 3.3 & 5.4 & 8.7 & NA \\
\hline Resin P & $\mathrm{mg} \mathrm{kg}^{-1}$ & 9.3 & 10.8 & 15.9 & NA \\
\hline $\mathrm{pH}\left(\mathrm{H}_{2} \mathrm{O}\right)$ & - & 5.8 & 5.8 & 7.8 & $5.4^{\mathrm{d}}$ \\
\hline
\end{tabular}

asoil property data from Li et al. (2015).

bIncluding coarse silt and fine sand (20-200 $\mu \mathrm{m})$.

'Water-soluble $P$.

${ }^{\prime}$ Measured before the experiment in this field.

resulting in soil $\mathrm{pH}$ values higher than the target values (Table 2). The $\mathrm{pH}$ values at the start of the incubation were 5.8 and 7.8 for the two soils with low and high lime, respectively. All soils were air-dried and sieved to $\leq 4 \mathrm{~mm}$ before use.

\section{Laboratory Incubation}

The incubation experiment was organised in a completely randomised design with two factors, i.e., biochar type and soil type. For each of the three soil types there were eight treatments: one control without any amendment (Con), one reference with TSP (ConP), one reference with potassium chloride $(\mathrm{KCl}$, ConK), and the five GBs (Table 1). The 24 treatment combinations were replicated 12 times to allow destructive sampling of three replicates each time at week $1,4,8$, and 16 after the start of the incubation.
The GB or TSP was added at $138.5 \mathrm{mg} \mathrm{P} \mathrm{kg}^{-1}$ soil, equivalent to $90 \mathrm{~kg} \mathrm{P} \mathrm{ha}^{-1}$ assuming a distribution in $5-\mathrm{cm}$ topsoil with a bulk density of $1.3 \mathrm{~g} \mathrm{~cm}^{-3}$. An exception was the STR treatment, where the material was applied at $69.3 \mathrm{mg} \mathrm{P} \mathrm{kg}^{-1}$ soil to limit the amount of $\mathrm{K}$ added because of its high $\mathrm{K}$-to-P ratio. The $\mathrm{KCl}$ was applied in a solution at $1,000 \mathrm{mg} \mathrm{K} \mathrm{kg}^{-1}$ soil. The GB or fertiliser was mixed with $200 \mathrm{~g}$ soil (dry weight basis) in polyethylene bags. After thorough mixing, the soil was moistened with deionised water to $60 \%$ of the water-holding capacity and kept at $10^{\circ} \mathrm{C}$ for 16 weeks in a dark room. During the whole period, the bags were kept open to allow gas exchange, and deionised water was added regularly to maintain the soil moisture on a weight basis. The sampled soil was analysed for water-, bicarbonate-, and resinextractable inorganic $\mathrm{P}$ and $\mathrm{pH}$ in the soil (see below).

To evaluate the $\mathrm{P}$ availability after different wetting-drying treatments of the GB during storage, four additional treatments were included using a straw GB that was originally sampled in dry form. Mixing of the straw GB with water was done on a weight:weight basis. The treatments were as follows: STR1, the straw GB was mixed with water at 1:1 and stored in moist form at $20^{\circ} \mathrm{C}$ in a closed container before initiation of the incubation experiment; STR2, the GB was mixed with water at 1:1, stored at $20^{\circ} \mathrm{C}$ in a closed container for 4 weeks, then air-dried at $20^{\circ} \mathrm{C}$ for 4 weeks and rewetted again (1:1) before the incubation; STR3, the GB was mixed with water at 2:1 and treated similarly as STR1; and STR4, the GB was applied directly in dry form. The straw GB for these extra treatments was from a batch different from STR and showed a slightly higher $\mathrm{P}$ concentration $4.3 \mathrm{~g} \mathrm{P} \mathrm{kg}^{-1} \mathrm{DM}$. The straw GB in these treatments was also applied at $69.3 \mathrm{mg} \mathrm{P} \mathrm{kg}^{-1}$ soil. The incubation, sampling, and analyses were the same as in the main incubation experiment.

\section{Mini-Plot Field Experiment}

The mini-plot field experiment was conducted at Research Centre Foulum, Aarhus University, Denmark. The field had previously been a grass-clover ley without $\mathrm{P}$ fertilisation for more than 5 years. The texture of the top $25 \mathrm{~cm}$ of this soil was loamy sand with $8.6 \%$ clay, bicarbonate extractable Olsen $\mathrm{P}$ was $24 \mathrm{mg} \mathrm{P} \mathrm{kg}$ (Olsen et al., 1954), and $\mathrm{pH}\left(\mathrm{H}_{2} \mathrm{O}\right)$ was 5.4 at the start of the 
experiment (Table 2). According to our experience, this soil was a medium-to-low P status soil in Denmark, having a P status in the lowest $25 \%$ quantile based on two surveys across Danish agricultural soils (Rubæk et al., 2013). In spring 2014, PVC cylinders (30 cm height and inner diameter) were inserted to $25 \mathrm{~cm}$ depth in the field with $45 \mathrm{~cm}$ intervals in four blocks.

The mini-plot experiment was organised in a completely randomised block design consisting of 4 blocks and 11 treatments: 1 control without any amendment (Con), 2 reference treatments with monopotassium phosphate $\left(\mathrm{KH}_{2} \mathrm{PO}_{4}, \mathrm{MP}\right)$ at 30 and $60 \mathrm{~kg} \mathrm{P} \mathrm{ha}^{-1}$, respectively, and $4 \mathrm{GBs}$ (POUL was excluded due to insufficient amounts available) at the same $\mathrm{P}$ rates as in the MP treatment (Table 3). The top $15 \mathrm{~cm}$ soil in each plot was removed and mixed thoroughly with the GB/ fertiliser in a bucket. The soil was divided into three portions of approximately the same size. Each portion was then returned to the mini-plot separately and compacted slightly. Twenty-eight seeds of spring barley (Hordeum vulgare L.; cv. Quench) were sown in two rows on 29 April 2014. Barley was also sown around the plots at the same rate the same day. After sowing, all plots were supplied with nutrient solutions (without $\mathrm{P}$ ), containing $150 \mathrm{~kg} \mathrm{~N} \mathrm{ha}^{-1}$ as ammonium nitrate $\left(\mathrm{NH}_{4} \mathrm{NO}_{3}\right), 150 \mathrm{~kg} \mathrm{~K} \mathrm{ha}^{-1}$ as $\mathrm{KCl}$ and sufficient amounts of $\mathrm{S}, \mathrm{Mg}, \mathrm{Ca}, \mathrm{Mn}, \mathrm{Zn}, \mathrm{B}, \mathrm{Cu}$, and Mo. The barley was hand-cut at maturity on 7 August 2014 and dried $\left(80^{\circ} \mathrm{C}\right)$ for determination of total DM. Grain and straw were separated for determination of grain and straw DM yield. After harvest, three soil cores (dia. $2 \mathrm{~cm}$ ) were taken from each plot at $0-13 \mathrm{~cm}$ depth and pooled to one sample for analysis of $\mathrm{pH}$, water-, bicarbonate-, and resin-extractable inorganic $\mathrm{P}$ (see below).

\section{Biochar, Soil, and Plant Analysis}

Total $\mathrm{C}$ and $\mathrm{N}$ in the GB or soil were determined by an elemental analyser (LECO Corporation, MI, USA). Total P, K, Ca, Mg, and Fe in the GB were measured by inductively coupled plasma-optical emission spectroscopy (ICP-OES, iCAP 6000 series, Thermo Fisher Scientific, UK) after sample digestion in a mixture of nitric acid $\left(\mathrm{HNO}_{3}\right)$, hydrogen peroxide $\left(\mathrm{H}_{2} \mathrm{O}_{2}\right)$, and hydrofluoric acid (HF) in a microwave digestion system at $210^{\circ} \mathrm{C}$ (Li et al., 2016).

TABLE 3 | Treatment description and application rates of the gasification biochars (GBs)/fertiliser in the field experiment.

\begin{tabular}{|c|c|c|c|}
\hline Treatment & Description & $\begin{array}{c}\text { Fertiliser/GB } \\
\text { Mg ha }^{-1}\end{array}$ & $\begin{array}{c}\text { P rate } \\
\text { kg ha }^{-1}\end{array}$ \\
\hline Con & No amendment & 0 & 0 \\
\hline MP30 & $\mathrm{KH}_{2} \mathrm{PO}_{4}$ & 0.13 & 30 \\
\hline MP60 & $\mathrm{KH}_{2} \mathrm{PO}_{4}$ & 0.26 & 60 \\
\hline STR30 & Straw GB & 7.50 & 30 \\
\hline STR60 & Straw GB & 15.00 & 60 \\
\hline NUT30 & Shea nut shell GB & 3.43 & 30 \\
\hline NUT60 & Shea nut shell GB & 6.86 & 60 \\
\hline SSA30 & Straw-sewage sludge A GB & 1.16 & 30 \\
\hline SSA60 & Straw-sewage sludge A GB & 2.31 & 60 \\
\hline SSB30 & Straw-sewage sludge B GB & 1.15 & 30 \\
\hline SSB60 & Straw-sewage sludge B GB & 2.31 & 60 \\
\hline
\end{tabular}

Selected GB properties can be found in Table 1.
The total P in the barley straw and grain was measured using the same procedure but without HF in the digestion process.

For water-extractable P in GB or soil, $1 \mathrm{~g}$ sample was extracted in $50 \mathrm{~mL}$ deionised water for $1 \mathrm{~h}\left(20^{\circ} \mathrm{C}\right)$ and then separated by centrifugation for $10 \mathrm{~min}(1,831 \times g) .1 \mathrm{~mL}$ of the $50 \mathrm{~mL}$ water was applied to the GB sample $24 \mathrm{~h}$ before the extraction. In soil samples, $\mathrm{P}$ was also extracted with $0.5 \mathrm{M} \mathrm{NaHCO}_{3}$ (Olsen et al., 1954) and with anion exchange resin membranes (resin-extractable $\mathrm{P}$ ). For resin-extractable $\mathrm{P}$, two resin strips $(60 \times 10 \mathrm{~mm}$, in bicarbonate form) were mixed with $30 \mathrm{~mL}$ deionised water and soil (equivalent to $c a .2 \mathrm{~g}$ dry soil) in a $50 \mathrm{~mL}$ centrifuge tube. The tube was shaken end over end at $25^{\circ} \mathrm{C}$ for $17 \mathrm{~h}$. The resin strips were removed and rinsed with water before the extracted $\mathrm{P}$ was eluted with $0.5 \mathrm{M} \mathrm{HCl}$ (modified from Kouno et al., 1995). All $\mathrm{P}$ concentrations were then measured by spectrophotometry using the molybdate blue method essentially as described for water analysis (ISO 6878:2004, 2004). Soil pH was measured after mixing of soil with water $(1: 2.5, \mathrm{w}: \mathrm{v})$ for $1 \mathrm{~h}$. Soil $\mathrm{pH}$ and resin-extractable $\mathrm{P}$ were measured on moist soil samples right after sampling while the other $\mathrm{P}$ analyses were carried out with air-dried soil.

The recovery rate (\%) of applied $\mathrm{P}$ in the soil-extractable $\mathrm{P}$ pools was calculated by subtracting the mean extractable $\mathrm{P}$ concentration in the control soil from that in the amended soil at the same sampling, which was then divided by the corresponding $\mathrm{P}$ application rate. Additionally, by taking the ratio between the $\mathrm{P}$ recovery rate from biochar and that from the corresponding TSP treatment, relative extractability (\%) of $\mathrm{P}$ by resins was calculated to indicate the fertiliser value of added GBs. The $\mathrm{P}$ recovery rate (\%) in the spring barley total aboveground biomass in the miniplot experiment was calculated accordingly.

\section{Statistical Analysis}

Statistical analyses were performed using the R software (R Core Team, 2015) at significance level $\alpha=0.05$. Two-way analysis of variance (ANOVA) revealed a significant interaction effect of biochar and soil type on the measured soil $\mathrm{pH}$, water-, bicarbonate-, and resin-extractable $\mathrm{P}$ in the incubation experiment. To facilitate interpretation of the biochar effect on soil $\mathrm{pH}$ and extractable $\mathrm{P}$, results of one-way ANOVA for the soil $\mathrm{pH}$ and $\mathrm{P}$ data for each soil type were presented. Because the two-way ANOVA in the mini-plot experiment indicated no significant effect of either the biochar or the application rate on crop measurements, results presented were from one-way ANOVA of all biochar-rate treatment combinations. Treatment effects were then analysed by multiple comparison with the glht function from the multcomp package (Hothorn et al., 2008). The potential relation between the soil resin-extractable $\mathrm{P}$ concentration and $\mathrm{pH}$ was explored using linear regression in $\mathrm{R}$.

\section{RESULTS}

\section{Varying N, P, K, and C Contents in GBs}

As expected, the concentrations of macronutrients ( $\mathrm{N}, \mathrm{P}$, and $\mathrm{K}$ ) and $\mathrm{C}$ in GBs varied among the types of feedstocks (Table 1). The total $\mathrm{N}$ in all GBs was $0.3-1.3 \%$. NUT had the highest total N content. The highest $\mathrm{P}$ concentration $\left(57 \mathrm{~g} \mathrm{~kg}^{-1} \mathrm{DM}\right)$ was measured in 
POUL, and POUL also had the smallest fraction of water-soluble $\mathrm{P}$ (WSP) $(<0.1 \%$ of the total P) of the five GBs. The lowest $\mathrm{P}$ concentration was observed in STR at $4 \mathrm{~g} \mathrm{~kg}^{-1} \mathrm{DM}$, of which $8.6 \%$ was water-soluble. NUT contained $9 \mathrm{~g}$ total $\mathrm{P} \mathrm{kg}^{-1} \mathrm{DM}$ and had the highest fraction of WSP (23\%) of all GBs. No difference in total P was seen for the two sludge GBs $\left(26 \mathrm{~g} \mathrm{~kg}^{-1} \mathrm{DM}\right.$ for both SSA and SSB) despite the different methods used to precipitate $\mathrm{P}$ during wastewater treatment, but the fraction of WSP in SSB (4\%) was about eight times higher than in SSA (0.5\%). The total $\mathrm{K}$ concentration was in the range $51-91 \mathrm{~g} \mathrm{~K} \mathrm{~kg}^{-1} \mathrm{DM}$. The total C content ranged from $9 \%$ in POUL to $59 \%$ in NUT. Additionally, POUL showed a much higher Ca concentration than the other GBs, 156 vs. $15-53 \mathrm{~g} \mathrm{Ca} \mathrm{kg}^{-1} \mathrm{DM}$, but STR had the highest Ca:P molar ratio at 5.3. SSA and SSB showed higher Fe concentrations than the others, $24-31$ vs. 2-9 $\mathrm{g} \mathrm{Fe} \mathrm{kg}^{-1} \mathrm{DM}$, as well as high Fe:P molar ratios of $0.5-0.7$.

\section{pH Increase in GB-Amended Soils}

The different GBs were able to increase $\mathrm{pH}$ in the three soils to varying extents (Table 4). In general, the increase in $\mathrm{pH}$ was more pronounced when adding GBs to the acid sandy soil than to the more clayey or alkaline soils. STR and NUT were added in much larger amounts than the other GBs (Table 1) and these two treatments significantly increased soil $\mathrm{pH}(\mathrm{p}<0.05)$ in the first week by $0.9-1.1,1.8-2.0$ and $0.6-0.9$ units in the Aarup, Jyndevad E, and Jyndevad $\mathrm{P}$ soil, respectively. A weaker, but significant, $\mathrm{pH}$ increase was also seen after addition of POUL, SSA, and SSB to the acid Aarup and Jyndevad E soil ( $p<0.05$ ), but not in the alkaline Jyndevad P soil. Both sludge biochars displayed the same effect on $\mathrm{pH}$ in all soils. In contrast to biochars, added mineral fertilisers tended to reduce soil $\mathrm{pH}$. The differences among treatments in soil $\mathrm{pH}$ in the first week persisted throughout the 16-week incubation with little variation.

\section{Available $P$ in the Three Soils}

The resin-extractable $\mathrm{P}$ (resin-P) was compared with the $\mathrm{P}$ extracted by $0.5 \mathrm{M} \mathrm{NaHCO}_{3}$ (Olsen P) or by water (WSP) in this study. Only the resin-P data are presented in Figure 1, while the Olsen P and WSP can be found in Figures S1 and S2 in Supplementary Material. After 1 week, 68, 68, and $71 \%$ of the $\mathrm{P}$ applied as TSP was recovered as resin-P in the two acid soils and the alkaline soil, respectively (Figure 1). The recovery in all TSP fertilised soils then declined and reached a stable level. In the Aarup soil, the recovery declined from 68 to 55\% (from week 1 to 4 ) and then declined further and stabilised at $48 \%$ in weeks 8 and 16. In the Jyndevad $\mathrm{E}$ and $\mathrm{P}$ soils, the decline of resin-P was rapid during the first 4 weeks, and the recovery rates were 43 and $52 \%$ after 16 weeks, respectively.

Both the absolute concentration and the recovery rate of resin- $\mathrm{P}$ in the amended soils varied among the different biochars on all three soil types (Figure 1). Similar to the TSP treatment, an initial decline in resin-P recovery was seen in the POUL treatment within the first 4 weeks, which subsequently (i.e., weeks 4-16) stabilised at 27-31, 20-24, and 23-28\% for the Aarup, and Jyndevad $\mathrm{E}$ and $\mathrm{P}$ soils, respectively. The resin-P recovery from SSA and SSB was similar and constantly low, i.e., $<14 \%$ throughout the incubation in all three soils, although they contained the second highest amount of P after POUL of the five GBs (Table 1). The P recovery from shea nut shell GB (NUT) developed differently over time across the three soils. It stayed constant at $22 \%$ in the Aarup soil, declined from 29 to about $20 \%$ in the Jyndevad E soil, but increased from 28 to $38 \%$ in the alkaline Jyndevad P soil during the 16-week incubation. The biochar from gasified straw (STR) showed a slightly increasing resin-P recovery in Aarup and Jyndevad E soil and strongly increasing rates in the alkaline Jyndevad P soil, from 34 to $49 \%$ over 16 weeks, which almost matched the recovery rate of $\mathrm{P}$ from TSP, at $52 \%$.

Resin-P extractability in soils amended with GBs (relative to TSP) was affected by soil types, in particular for STR and NUT (Figure 2). The relative $\mathrm{P}$ extractability in the STR treatment in the alkaline sandy soil (Jyndevad P) was significantly higher than in the two acid soils and increased from 49 to $94 \%$ from week 1 to 16 . A significantly greater relative $\mathrm{P}$ extractability was also observed for NUT 16 weeks after being applied to the alkaline soils with a $\mathrm{pH}$ of 7.8 compared to the two acid soils with pH 5.8 (Figure 2B). In the POUL treatment, the relative $\mathrm{P}$

TABLE 4 | Soil pH $\left(\mathrm{H}_{2} \mathrm{O}\right)$ measured at 1, 4, 8, and 16 weeks after application of gasification biochars/fertiliser to the three soils in the incubation experiment.

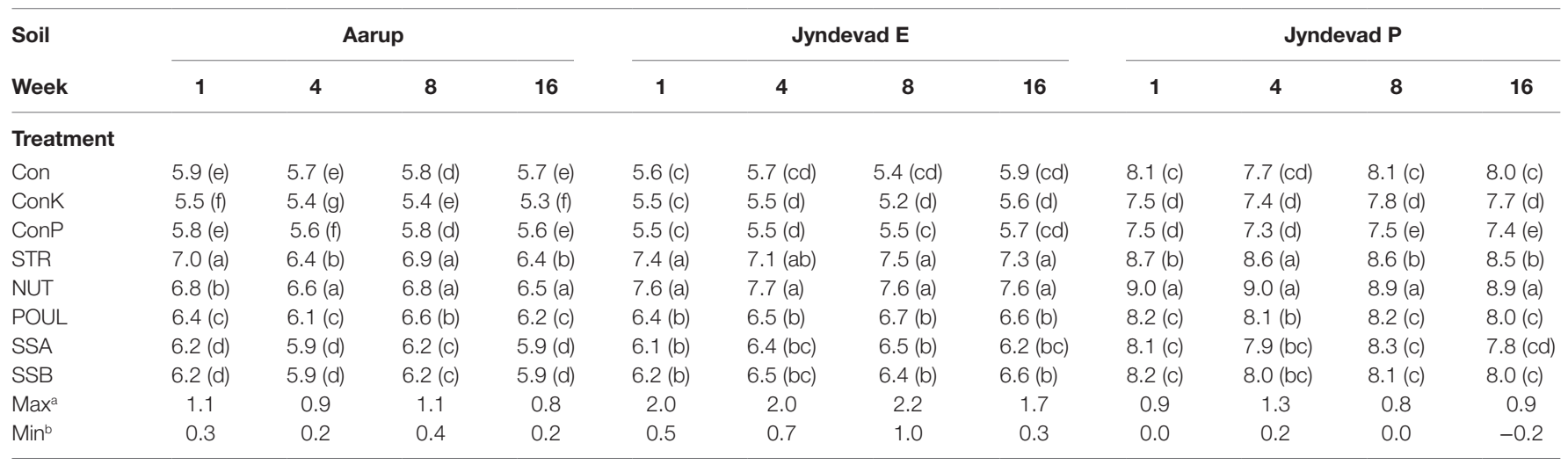

For treatment details see Table 1. Same letters within the same column indicate no significant differences $(p>0.05, n=3)$.

a Maximum increase in soil $\mathrm{pH}$ compared to Con among the five biochar treatments.

${ }^{b}$ Minimum increase in soil $\mathrm{pH}$ compared to Con among the five biochar treatments. 


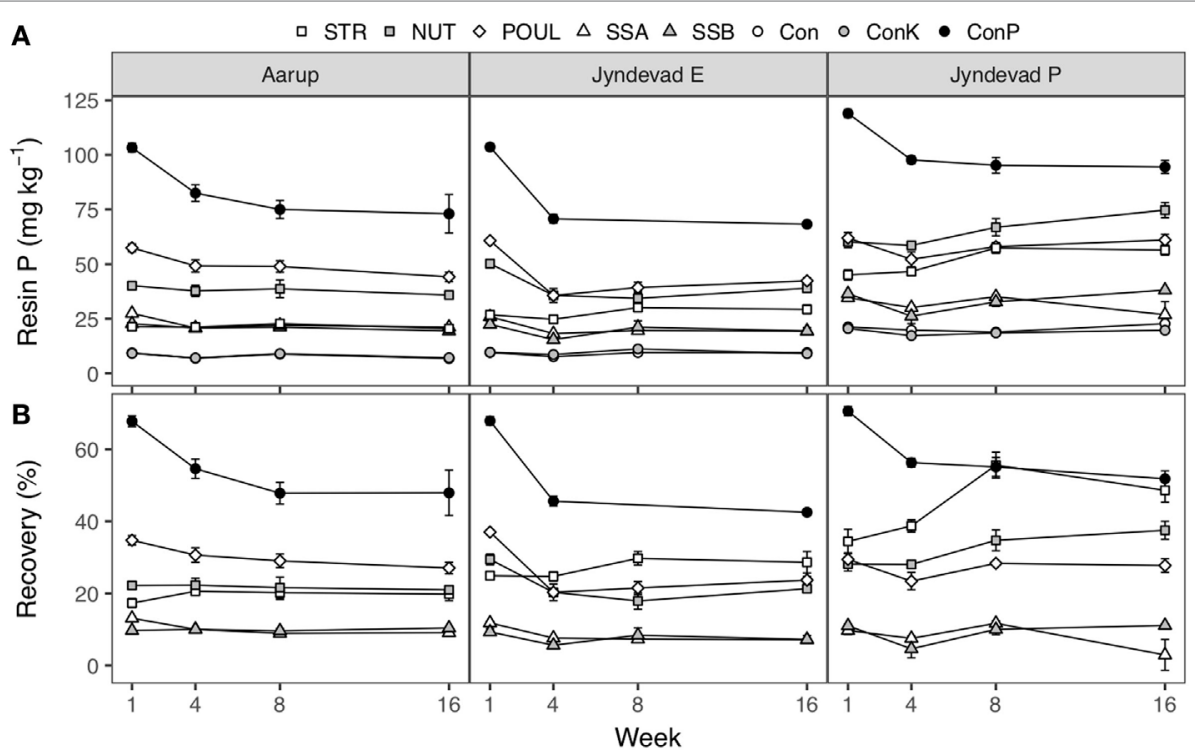

FIGURE 1 | Concentration (A) of resin-extractable $\mathrm{P}$ and recovery rate (B) as resin-P from applied gasification biochars/fertilisers in the three soils in the incubation experiment. Bars are SEs $(n=3)$. For treatment details see Table 1.

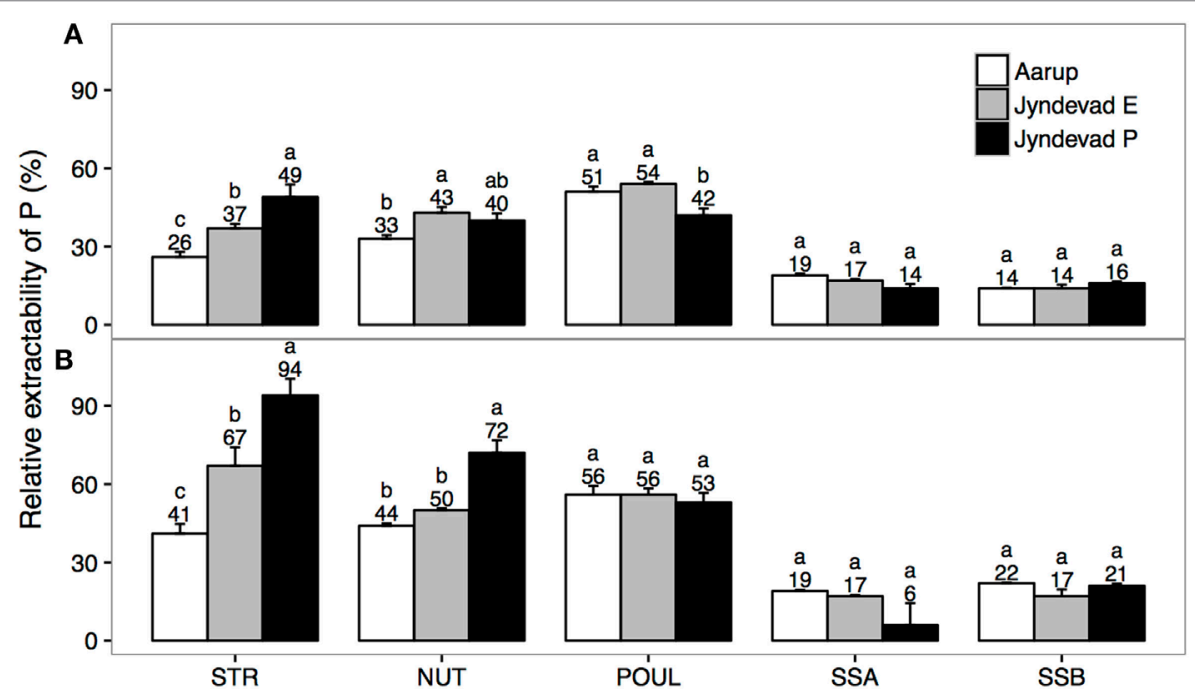

FIGURE 2 | Relative extractability of P by resins in soils amended with gasification biochars (GBs) in week 1 (A) and 16 (B) in the incubation experiment. It is calculated as the ratio (\%) of recovery of applied P between GB and corresponding triple superphosphate treatments. The values and error bars are mean and SEs $(n=3)$. Same letters above each GB indicate no significant differences among the soils $(p>0.05)$. For treatment details see Table 1.

extractability was significantly lower in the alkaline soil than in the acid soils in week 1 but had caught up with the latter after 16 weeks. Furthermore, for STR and NUT significantly higher $\mathrm{P}$ extractability was seen in the sandy Jyndevad E soil compared with the clay-rich Aarup soil (Figure 2A).

\section{No Effect of Moisture in GB on P Availability}

The resin-P recovery rates from soils amended with the straw GB subjected to different wetting and drying treatments did not differ significantly from each other at most of the measurement dates
(Figure 3). Moreover, the temporal trends of both the absolute values of resin-P and the recovery rates in these treatments were similar to the observations for the STR treatment in the main incubation experiment (Figure 1).

\section{Positive Correlation: Soil pH and Resin-P}

A significant positive relationship was identified between soil $\mathrm{pH}$ and resin-P concentrations in each incubated soil, especially after amendment with GBs with low P contents, i.e., STR, NUT, SSA, and SSB (Figure 4). The resin-P concentration tended to increase more rapidly with $\mathrm{pH}$ in the alkaline Jyndevad $\mathrm{P}$ soil. 
口 STR1 a STR2 $\triangle$ STR3 $\triangle$ STR4 $\circ$ Con

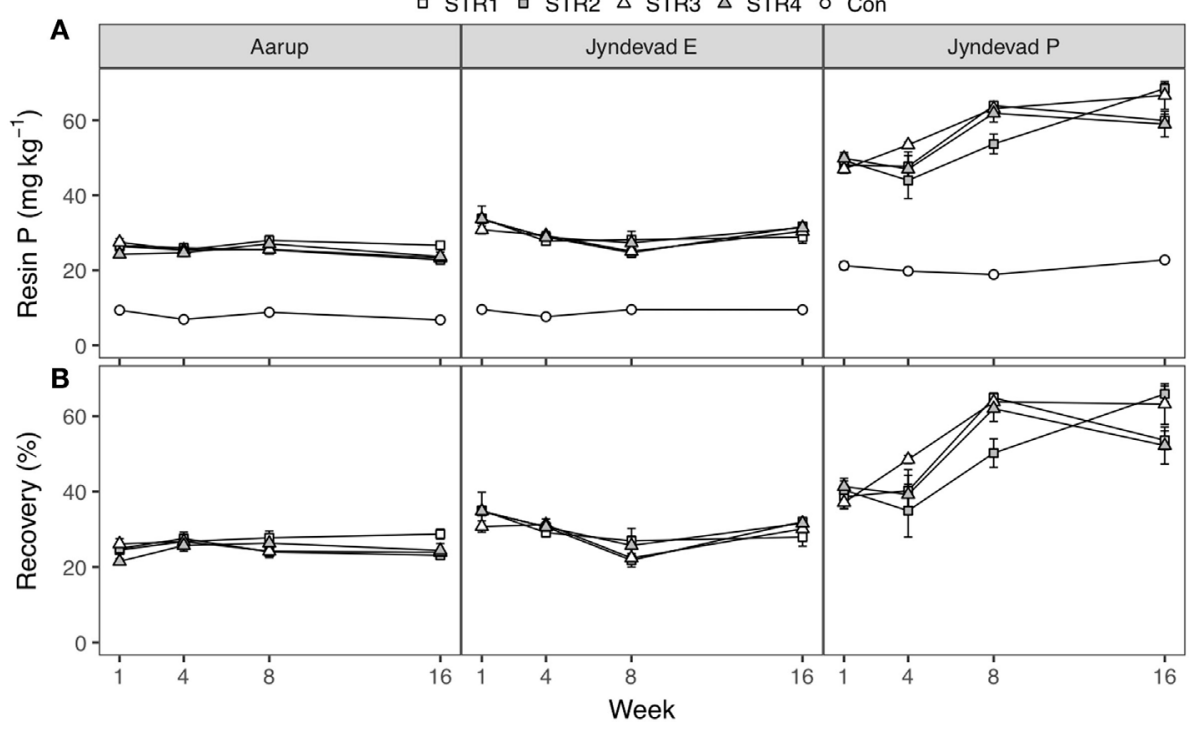

FIGURE 3 | The concentration (A) of resin-extractable $P$ and the recovery rate (B) as resin-P from applied straw gasification biochars (GBs) in the three soils in the extra wetting-drying treatments of the incubation experiment. STR1-4 refer to the straw GBs that were subject to different wetting and drying treatments: STR1, the biochar was mixed with water at 1:1 (w:w) before initiation of the incubation; STR2, the biochar was mixed with water at 1:1, air dried, and watered again at 1:1; STR3, the biochar was mixed with water at 2:1; and STR4, the original dry GB. The biochars were applied at $69.3 \mathrm{mg} \mathrm{P} \mathrm{kg}^{-1}$ soil. Con is the control without amendment. Bars are SEs $(n=3)$.

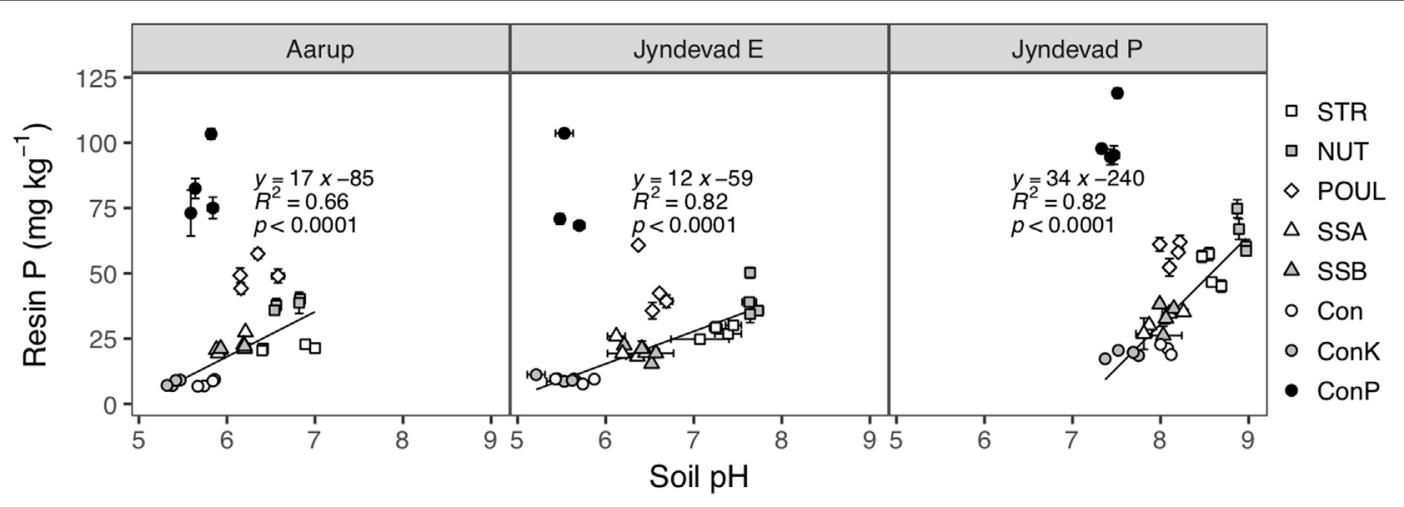

FIGURE 4 | Correlation between the concentration of resin-extractable P and pH in the three soils after gasification biochar application. Two treatments, i.e., mineral $\mathrm{P}$ fertiliser (ConP, black circles) and the poultry manure biochar (POUL, diamonds), were excluded from the regression analysis, and data from all four sampling dates are included. Error bars are SEs $(n=3)$. For treatment details see Table 1.

The coefficient of determination for such regression was $0.66-0.82$ in the three tested soils (Figure 4) compared to only 0.26-0.39 for the regression between the Olsen $\mathrm{P}$ and $\mathrm{pH}$ (data not shown).

\section{No Adverse Effect of GB on Barley Growth}

In the mini-plot experiment, only a slight increase was observed in crop yield, $\mathrm{P}$ uptake, soil $\mathrm{pH}$, and available $\mathrm{P}$ after harvest in either GB or mineral fertiliser treatments, and few of these were statistically significant compared with the control (Figures 5-7; $p>0.05$ ). Compared to the control, we only observed a significantly higher soil resin-P level after barley in the SSA treatment (applied at $60 \mathrm{~kg} \mathrm{P} \mathrm{ha}{ }^{-1}$, Figure 7A), higher Olsen-P in the two mineral $\mathrm{P}$ fertiliser treatments (Figure 7B) and higher soil $\mathrm{pH}$ in the STR treatment (applied at $30 \mathrm{~kg} \mathrm{P} \mathrm{ha}^{-1}$, Figure 7C). Additionally, soil $\mathrm{pH}$ was raised to a level significantly higher in STR than in MP and SSB treatments when applied at the same $\mathrm{P}$ dose of $30 \mathrm{~kg} \mathrm{P} \mathrm{ha}^{-1}$. Significantly higher levels of soil resin-P were also seen when NUT and SSA were applied at a high dose $\left(60 \mathrm{~kg} \mathrm{P} \mathrm{ha}^{-1}\right)$ compared to the STR treatment at a lower dose (30 kg P ha ${ }^{-1}$ ), which was however not clearly observed in the Olsen P (Figures 7A,B). The grain yield was 7.3 and 8.0-9.1 Mg $\mathrm{ha}^{-1}$ in the control and the amended treatments, respectively, but not significantly different from each other (Figure 5). The variation in grain $\mathrm{P}$ concentration was very small, $2.65-2.89 \mathrm{~g} \mathrm{P} \mathrm{kg}^{-1}$. 


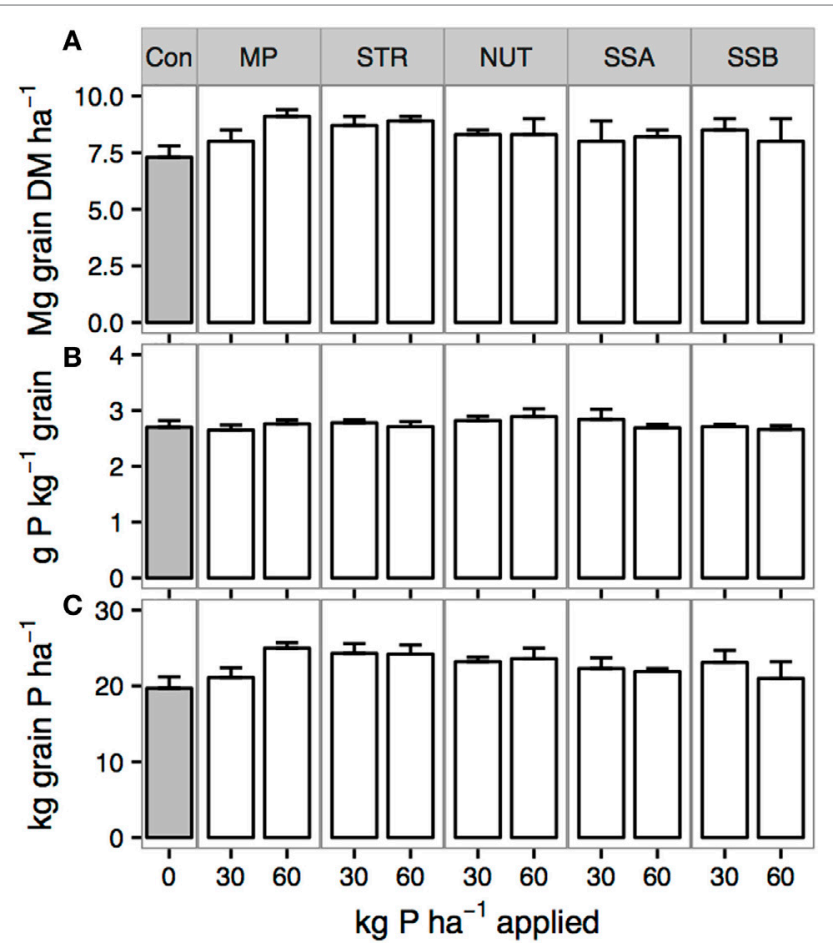

FIGURE 5 | Dry matter (DM) (A), P concentration (B), and P uptake (C) in spring barley grain in the field mini-plots amended with $\mathrm{KH}_{2} \mathrm{PO}_{4}$ or four gasification biochars at 30 and $60 \mathrm{~kg} \mathrm{Pha}^{-1}$. An analysis of variance showed that the $p$ values for treatment effects on grain $\mathrm{DM}, \mathrm{P}$ concentration, and $\mathrm{P}$ uptake were 0.5, 0.5, and 0.2, respectively. Significant block effects were also identified on grain DM and P concentration $(p=0.03$ and 0.0006 , respectively). Error bars are SEs $(n=4)$. For treatment details see Table 3 .

Due to the small variation in $\mathrm{P}$ concentration, the trend of total grain $\mathrm{P}$ was similar to that of the grain yield, $20 \mathrm{~kg} \mathrm{P} \mathrm{ha}^{-1}$ in the control and $21-25 \mathrm{~kg} \mathrm{P} \mathrm{ha}^{-1}$ in the amended treatments, and the difference was not statistically significant.

\section{DISCUSSION}

\section{Composition of GBs}

Biochars contain considerable amounts of mineral nutrients and C, as shown in Table 1. It has been reported that biochars can be a direct source of macronutrients and micronutrients for crop production, such as P (Wang et al., 2012; Vassilev et al., 2013). However, the total $\mathrm{P}$ concentration varied considerably among the biochars of different origin. The review by Spokas et al. (2012) compiled total $\mathrm{P}$ concentrations in a number of biochars derived from feedstocks like agricultural residues, woody biomass, and animal manures ranging from 0.1 to $59 \mathrm{~g} \mathrm{P} \mathrm{kg}^{-1}$. Differences in total $\mathrm{P}$ in biochars might not only depend on the nutrient composition of the feedstock but also on the thermal conversion conditions (Spokas et al., 2012). The K concentration in these GBs was generally much higher than the $\mathrm{P}$ concentration, particularly in STR (Table 1). Therefore, not only P but also K needs to be considered when planning soil application of biochars to ensure sustainable utilisation of both $\mathrm{P}$ and $\mathrm{K}$. The tested GBs contained

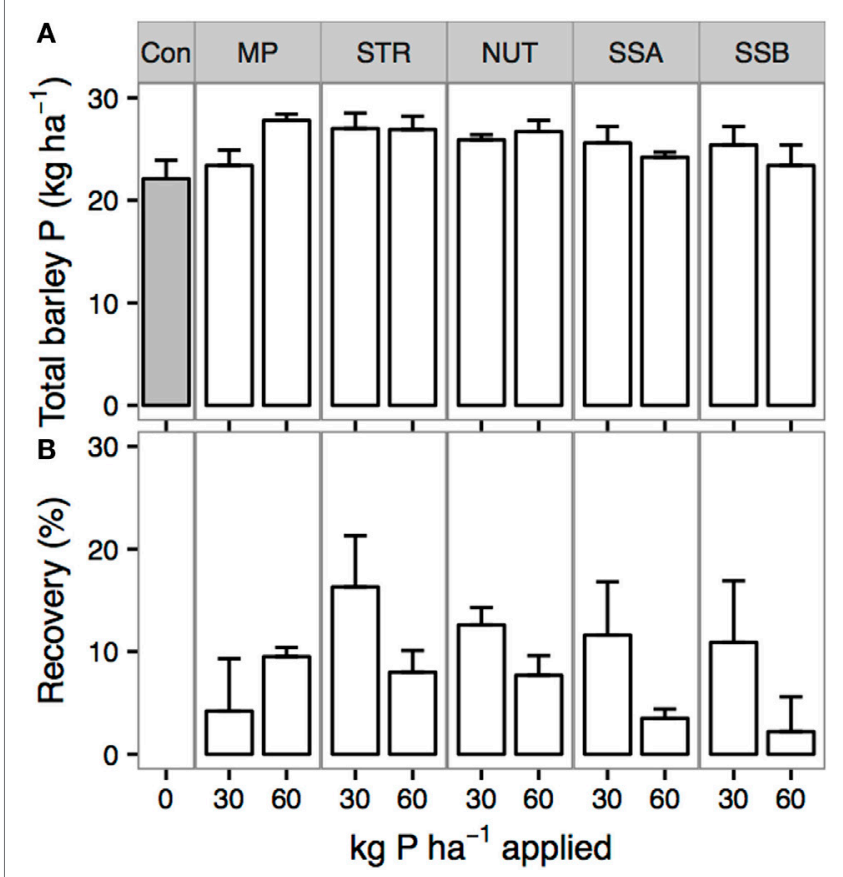

FIGURE 6 | P uptake in total aboveground biomass of spring barley (A) and corresponding $\mathrm{P}$ recovery rate as percentage of $\mathrm{P}$ input $\mathbf{( B )}$ in the field mini-plots amended with $\mathrm{KH}_{2} \mathrm{PO}_{4}$ or four gasification biochars at 30 and $60 \mathrm{~kg} \mathrm{P} \mathrm{ha}^{-1}$. An analysis of variance showed that the $p$ value for treatment effect on total P uptake was 0.1. Error bars are SEs $(n=4)$. For treatment details see Table 3 .

furthermore $0.3-1.3 \%$ total $\mathrm{N}$, which might be mineralised and used by crops, but Wang et al. (2012) showed decreasing $\mathrm{N}$ availability in biochars with increasing pyrolysis temperature. Due to the nature of incomplete combustion, there was $9-57 \%$ of total C in the tested GBs. Hansen et al. (2016) showed that application of biochars derived from the gasification of straw by the LT-CFB technology has the potential to increase $\mathrm{C}$ sequestration in soil.

\section{Effects of Moisture during GB Storage on P Availability}

Addition of water to the GB during storage can have large benefits by lowering the risk of self-ignition and minimising dusting during storage and spreading. One 16-week study reported that during different types of storage (dry/wet, open/airtight) of a $\mathrm{CaO}$-rich wood ash, the main chemical reaction was the hydration of $\mathrm{CaO}$ with water to form $\mathrm{Ca}(\mathrm{OH})_{2}$ (Supancic et al., 2014), but it is unclear how different storage types affect $\mathrm{P}$ availability in biochar or ash residues. We hypothesised that wetting and drying of the GB could also influence P solubility and the following availability of $\mathrm{P}$ in soil through possible recombination of ions in the wet phase followed by precipitation. This was clearly not the case in our study, since we observed almost no differences in $P$ availability after either dry or wet storage including wettingdrying events (Figure 3). The results might be different for other GBs, depending on their chemical composition, and this still needs further testing. 


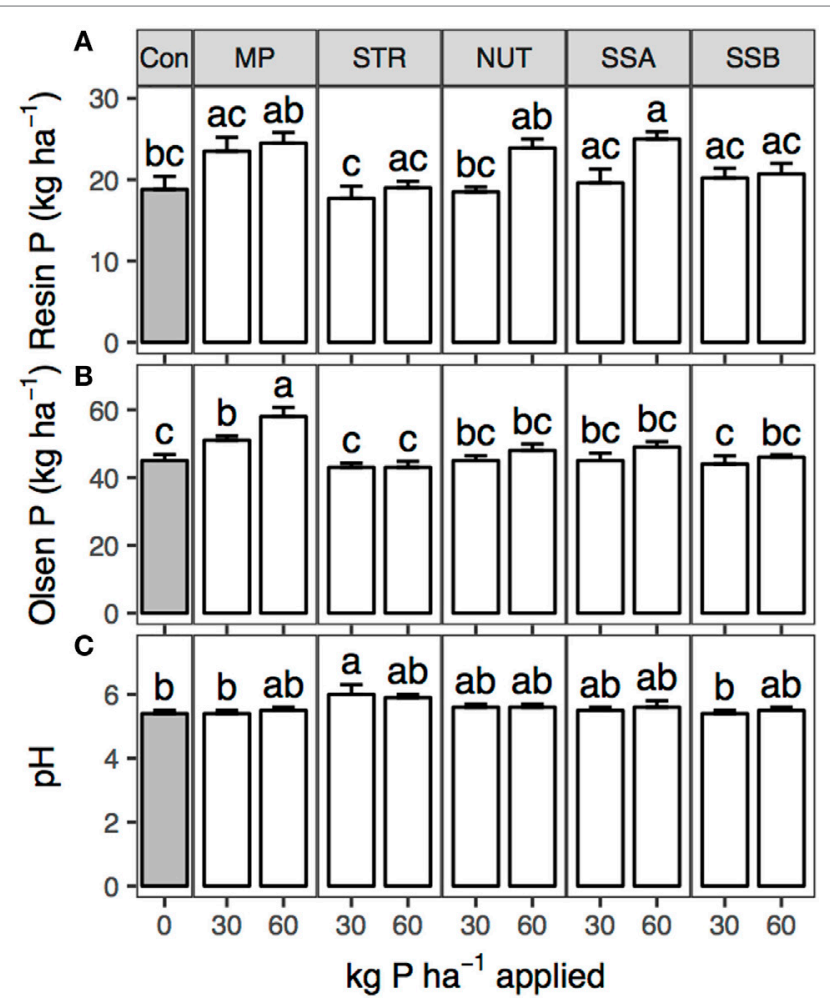

FIGURE 7 | Concentration of resin-extractable P (A) and Olsen P (B) in soil $(0-13 \mathrm{~cm})$ and soil $\mathrm{pH}$ (C) after harvest of spring barley in the field mini-plots amended with $\mathrm{KH}_{2} \mathrm{PO}_{4}$ or four gasification biochars at 30 and $60 \mathrm{~kg} \mathrm{P} \mathrm{ha}^{-1}$ Error bars are SEs $(n=4)$. Same letters indicate no significant differences $(p>0.05, n=4)$. For treatment details see Table 3 .

\section{Effect of GBs on Soil pH}

Soil $\mathrm{pH}$ increased to different extents in the three soils amended with the five GBs (Table 4). The increase in $\mathrm{pH}$ was most pronounced in the acid sandy soil with STR and NUT. The greater liming effect in these two treatments compared to the others was probably due to the higher application rates of STR and NUT (15.8-16.5 vs. 2.4-5.3 $\mathrm{g} \mathrm{DM} \mathrm{kg}^{-1}$ ) as we aimed for comparable $\mathrm{P}$ application rates with the biochars. Previous studies have reported that $\mathrm{pH}$ increased with the application rates of biochars ( $\mathrm{Xu}$ et al., 2014). In addition, the relatively higher increase in $\mathrm{pH}$ in the acid sandy soil than in soils with higher clay and $\mathrm{pH}$ levels might be due to a lower buffering capacity of the acid sandy soil. Equal doses of biochar increased soil $\mathrm{pH}$ more in acidic soils than alkaline soils in a meta-analysis (Biederman and Harpole, 2013). In contrast to the significant $\mathrm{pH}$ increase in the incubation experiment, the $\mathrm{pH}$ in our miniplots only increased significantly (i.e., by 0.6 units) in one treatment amended with STR applied at $30 \mathrm{~kg} \mathrm{P} \mathrm{ha}^{-1}$ (Figure 7). The insignificant $\mathrm{pH}$ increase in most treatments in this loamy sand soil with a low $\mathrm{pH}$ may be due to relatively lower application rates of GBs compared to those in the incubation study and because GBs were well mixed with the top $15 \mathrm{~cm}$ soil layer. In practice, biochars will not be so well mixed with soil under normal agricultural conditions and locally concentrations will be higher. Additionally, to ensure that $\mathrm{N}$ was not limiting the growth of spring barley, $\mathrm{NH}_{4} \mathrm{NO}_{3}$ was supplied at $150 \mathrm{~kg} \mathrm{~N} \mathrm{ha}^{-1}$ in the mini-plot experiment, and it is well known that $\mathrm{NH}_{4}{ }^{+}$ application may cause soil $\mathrm{pH}$ to decrease due to nitrification of ammonium (Barak et al., 1997). This may have counterbalanced the liming effect of the biochars.

\section{Effect of GBs on Soil Available P}

Total P in GBs varied from 4 (in STR) to $57 \mathrm{~g} \mathrm{~kg}^{-1}$ (in POUL), and the fraction of WSP ranged from $<0.1 \%$ (in POUL) to $22.6 \%$ (in NUT). However, both the total $\mathrm{P}$ and the WSP concentration do not necessarily reflect $\mathrm{P}$ availability after soil application (Spokas et al., 2012), as shown with POUL, where almost $40 \%$ of the applied $\mathrm{P}$ was recovered as resin-P in all three soils after 1 week despite its lower fraction of WSP (Figure 1; Table 1). Compared to direct analysis of $\mathrm{P}$ availability in the products by simple extractions, mixing biochar/ash residues with soil introduces important chemical and microbiological conditions for dissolution of $\mathrm{P}$ in the products. When evaluating the $\mathrm{P}$ availability after addition of P-containing materials, the $\mathrm{P}$ already present in the soil can be taken into account by including a control treatment and calculating apparent recoveries of the added $\mathrm{P}$.

The method of chemical extraction from soil samples with $0.5 \mathrm{M} \mathrm{NaHCO}_{3}$ (known as Olsen P) is widely used to indicate soil P availability (Jordan-Meille et al., 2012). Later developed soil $\mathrm{P}$ test methods such as anion exchange membrane (i.e., resin) extractable $\mathrm{P}$ may be more suitable to indicate plant-available $\mathrm{P}$, because the extraction process by resins resembles the plant-soil interactions by plant $\mathrm{P}$ uptake in soil, and the method is less dependent on soil types (Schoenau and Huang, 1991). In our study, the results by the resin-P method were more differentiated among treatments than Olsen $\mathrm{P}$ and water-extractable $\mathrm{P}$ regardless of soil types, although the general response pattern was the same for all three methods (Figure 1; Figures S1 and S2 in Supplementary Material). This may be related to the fact that the resin extraction was done on moist samples but the other two on dried samples. Therefore, only the resin-P data are discussed further to represent the available $\mathrm{P}$ in this study.

There was a clear effect of the gasification feedstock types on the $\mathrm{P}$ availability in soil. Generally, high recovery rates were achieved with the GB derived from manure, which accords well with other studies on pyrolysis biochar (Ippolito et al., 2015) and GB (Kuligowski et al., 2010). Wang et al. (2012) found constantly higher $\mathrm{P}$ recovery rates from biochars originating from manure compared to those produced from sewage sludge, which was confirmed in our study. This could be due to the presence of different chemical $\mathrm{P}$ compounds in the GB. The $\mathrm{P}$ is probably dominated by $\mathrm{Mg} / \mathrm{Ca}-\mathrm{P}$ in manure-based biochars (Wang et al., 2012,2015 ) and by Fe/Al-P in GB originating from sewage sludge (Parés-Viader et al., 2016). This was also reflected in the relatively high Mg:P molar ratio in POUL and in the high Fe contents and Fe:P molar ratios in SSA and SSB compared to the other GBs (Table 1).

The recovery rates and the relative extractability of $\mathrm{P}$ from NUT and STR varied among the different soils after the 16-week incubation, being significantly lower in the Aarup and Jyndevad 
E soils and higher in the alkaline Jyndevad $\mathrm{P}$ soil (Figure 2). Contrarily, those from POUL, SSA, and SSB seemed not to be strongly affected by the soil type. This implies that the fertiliser value of GBs may be dependent on both the feedstock and soil type.

Biochars can generally increase plant-available $\mathrm{P}$ in soil not only by the mere increase in available $\mathrm{P}$ introduced by $\mathrm{P}$ released from the material into the soil solution but also by altering the physico-chemical conditions of the soil, such as $\mathrm{pH}$, which in turn can influence the $\mathrm{P}$ availability in the native soil $\mathrm{P}$ pools. An increase in soil $\mathrm{pH}$ may not have the same effect on $\mathrm{P}$ availability in different soil types because of their different conditions for binding $\mathrm{P}$ arising from their mineralogy, organic matter content, nutrient status, and initial $\mathrm{pH}$ as shown in many studies (e.g., Haynes, 1982; Weng et al., 2011). In the three soils tested here, we found a significant positive and soil type-specific relationship between the resin-P concentration and $\mathrm{pH}$ in soil after addition of biochars with relatively low $\mathrm{P}$ contents (Figure 4). One possible explanation for this positive correlation is that the surfaces of the soil particles become more negatively charged with increased $\mathrm{pH}$ (deprotonation) and hence phosphate adsorption decreases with increasing pH (Devau et al., 2009; Murphy and Stevens, 2010). As pH increases following biochar application in the acid Aarup and Jyndevad E soils, P may become released from its tight binding with $\mathrm{Fe}$ and/or Al oxides (Cui et al., 2011; Macdonald et al., 2014) due to reduced solubility of the hydroxy-Al or -Fe species at around the neutral $\mathrm{pH}$ range (Haynes, 1982). In the alkaline soil (Jyndevad P) with a history of intensive lime applications, high contents of exchangeable calcium ions are expected to be present in the soil which might associate with the applied biochar. It has been shown previously that straw GB is able to increase cation exchange capacity of soils (Hansen et al., 2016). Therefore, the adsorption of $\mathrm{Ca}$ to biochars may weaken the binding between $\mathrm{Ca}$ and phosphate in this soil and thereby increase the $\mathrm{P}$ availability in combination with the effect of deprotonation induced by the higher $\mathrm{pH}$ (Devau et al., 2009). The rapid increase of resin- $\mathrm{P}$ with rising $\mathrm{pH}$ in the Jyndevad P soil was consistent with several previous studies, which also reported increasing $\mathrm{P}$ concentrations in the soil solution with elevated $\mathrm{pH}(>7)$ in several soil types, and demonstrated that $\mathrm{pH}$ is an important factor controlling the availability of $\mathrm{P}$ in soil (Haynes, 1982; Devau et al., 2009; Weng et al., 2011; Xu et al., 2014).

The different temporal patterns of available $\mathrm{P}$ that occurred for different GBs when added to different soils, especially the changes in alkaline Jyndevad P soil (Figure 1), could probably be explained by the various processes governing adsorption/ immobilisation and desorption/mobilisation of $\mathrm{P}$ needing varying lengths of time to reach equilibrium. For instance, there might be a net adsorption/immobilisation in soil in the 4-8 weeks after applying TSP as it readily dissolves (Figure 1). For STR in the Jyndevad P soil, there might be a net desorption/mobilisation of $\mathrm{P}$ during the first 8 weeks because STR may dissolve more slowly considering its higher $\mathrm{Ca}: \mathrm{P}$ ratio (Table 1), after which equilibrium might have been reached (Figure 1).

\section{Crop and Soil Response to GBs}

It has been acknowledged that biochar may have positive, negative, or no effect on crop production as influenced by many complex factors (Spokas et al., 2012; Biederman and Harpole, 2013; Macdonald et al., 2014). We demonstrated that there was no adverse impact on crop growth of the added biochars in doses (e.g., 30 and $60 \mathrm{~kg} \mathrm{P} \mathrm{ha}^{-1}$ ) corresponding to relevant $\mathrm{P}$ doses typically given as mineral $\mathrm{P}$ fertiliser to the studied soil. The $\mathrm{P}$ uptake (Figure 6) and grain yield (Figure 5) in the mini-plot experiment tended to be higher in the plots amended with mineral fertiliser or biochars than in the control, but were not significantly different. One reason for the insignificant response might be that the $\mathrm{P}$ status of the soil at $24 \mathrm{mg}$ Olsen- $\mathrm{P} \mathrm{kg}^{-1}$ was not low enough to limit the barley growth. Compared to this soil, a similar or higher level of Olsen-P is found in the majority (ca. 75\%) of Danish agricultural soils (Rubæk et al., 2013), where P fertilisers have been applied for several decades to build up and to maintain a sufficient level of available $\mathrm{P}$ in soil.

$\mathrm{P}$ fertilisers are applied by farmers to maintain a sufficient level of available $\mathrm{P}$ in soil, also in the longer term. A general positive recovery rate of $\mathrm{P}$ applied with biochars (Figure 6) indicates that they also contribute positively to available P in soil. After harvest, the resin-P level increased in the soil amended with mineral fertiliser, and the NUT and SSA biochar treatments (high rate) compared to the control, though only significantly in the SSA treatment. We therefore conclude that the tested biochars and the mineral fertiliser had only minor and barely significant impacts on the crop performance in this experiment, but the tested biochars will contribute to maintaining the level of available $\mathrm{P}$ in soil.

\section{CONCLUSION}

In this study, we evaluated plant $\mathrm{P}$ availability in contrasting soils amended with five biochars derived from biomass gasification via the LT-CFB technology. In a mini-plot experiment on a loamy sand soil, biochar application showed only insignificant positive effects on P uptake and yield of spring barley, probably due to sufficient soil $\mathrm{P}$ availability. In a 16-week incubation, considerable though varying amounts of $\mathrm{P}$ (about 10-50\%) from applied biochars were recovered as resin-extractable $\mathrm{P}$ in three different soils, demonstrating the varying ability of GBs to replace mineral $P$ fertilisers on agricultural land. A strong influence of the GB feedstock on P availability was observed. GBs derived from poultry manure, wheat straw and shea nut residues showed higher $\mathrm{P}$ extractability relative to TSP (indicating the fertiliser value) than sewage sludge-based GBs, i.e., $41-94 \%$ vs. $6-22 \%$ after 16 weeks. A significant $\mathrm{pH}$ increase was observed after biochar application, which was dependent on the dose applied, the initial soil $\mathrm{pH}$, and probably the buffering capacity of the soil. There was a significant positive correlation between available $\mathrm{P}$ and $\mathrm{pH}$ in soils amended with certain GBs with relatively low P contents (i.e., STR, NUT, SSA, and SSB), which proved the importance of soil $\mathrm{pH}$ in determining $\mathrm{P}$ availability. Wetting and drying of a straw GB during storage had no significant influence on the $\mathrm{P}$ availability following soil application, showing that wet storage is suitable in the practical handling of GBs. These results suggest that feedstock types 
and soil properties, e.g., soil $\mathrm{pH}$, are important for $\mathrm{P}$ availability after application of GBs.

\section{AUTHOR CONTRIBUTIONS}

GR, DM-S, and PS designed and performed the experiments. XL analysed the data and wrote the manuscript. GR, DM-S, and PS contributed to discussion and revision of the manuscript. TT and JA provided some biochar materials and information concerning the LT-CFB gasification and contributed to revision of the manuscript.

\section{ACKNOWLEDGMENTS}

We would like to thank Margit Paulsen and Mette S. Haferbier at Department of Agroecology, Aarhus University for technical

\section{REFERENCES}

Ahrenfeldt, J., Thomsen, T. P., Henriksen, U., and Clausen, L. R. (2013). Biomass gasification cogeneration - a review of state of the art technology and near future perspectives. Appl. Therm. Eng. 50, 1407-1417. doi:10.1016/j.applthermaleng. 2011.12.040

Barak, P., Jobe, B. O., Krueger, A. R., Peterson, L. A., and Laird, D. A. (1997). Effects of long-term soil acidification due to nitrogen fertilizer inputs in Wisconsin. Plant Soil 197, 61-69. doi:10.1023/A:1004297607070

Biederman, L. A., and Harpole, W. S. (2013). Biochar and its effects on plant productivity and nutrient cycling: a meta-analysis. GCB Bioenergy 5, 202-214. doi:10.1111/gcbb.12037

Crane-Droesch, A., Abiven, S., Jeffery, S., and Torn, M. S. (2013). Heterogeneous global crop yield response to biochar: a meta-regression analysis. Environ. Res. Lett. 8, 1-8. doi:10.1088/1748-9326/8/4/044049

Cui, H. J., Wang, M. K., Fu, M. L., and Ci, E. (2011). Enhancing phosphorus availability in phosphorus-fertilized zones by reducing phosphate adsorbed on ferrihydrite using rice straw-derived biochar. J. Soil Sediment 11, 1135-1141. doi:10.1007/s11368-011-0405-9

Devau, N., Le Cadre, E., Hinsinger, P., Jaillard, B., and Gerard, F. (2009). Soil pH controls the environmental availability of phosphorus: experimental and mechanistic modelling approaches. Appl. Geochem. 24, 2163-2174. doi:10.1016/j. apgeochem.2009.09.020

Hansen, V., Müller-Stöver, D., Ahrenfeldt, J., Holm, J. K., Henriksen, U. B., and Hauggaard-Nielsen, H. (2015). Gasification biochar as a valuable by-product for carbon sequestration and soil amendment. Biomass Bioenergy 72, 300-308. doi:10.1016/j.biombioe.2014.10.013

Hansen, V., Müller-Stöver, D., Munkholm, L. J., Peltre, C., Hauggaard-Nielsen, H., and Jensen, L. S. (2016). The effect of straw and wood gasification biochar on carbon sequestration, selected soil fertility indicators and functional groups in soil: an incubation study. Geoderma 269, 99-107. doi:10.1016/j.geoderma. 2016.01.033

Haynes, R. J. (1982). Effects of liming on phosphate availability in acid soils - a critical-review. Plant Soil 68, 289-308. doi:10.1007/Bf02197935

Holford, I. C. R. (1997). Soil phosphorus: its measurement, and its uptake by plants. Aust. J. Soil Res. 35, 227-239. doi:10.1071/S96047

Hothorn, T., Bretz, F., and Westfall, P. (2008). Simultaneous inference in general parametric models. Biometrical J. 50, 346-363. doi:10.1002/bimj.200810425

Ippolito, J. A., Spokas, K. A., Novak, J. M., Lentz, R. D., and Cantrell, K. B. (2015). "Biochar elemental composition and factors influencing nutrient retention," in Biochar for Environmental Management: Science, Technology and Implementation, 2nd Edn, eds J. Lehmann and S. Joseph (London and New York: Routledge), 139-163.

ISO 6878:2004. (2004). Water Quality: Determination of Phosphorus - Ammonium Molybdate Spectrometric Method. ISO International Organization for Standardisation. support during the experiment. We are also grateful to collaborators at DONG Energy for providing gasification biochar samples.

\section{FUNDING}

This study was financially supported by the "Fuel Flexible, Efficient and Sustainable Low Temperature Biomass Gasification" project, funded by the Danish Energy Agency (Energistyrelsen) through the EUDP programme.

\section{SUPPLEMENTARY MATERIAL}

The Supplementary Material for this article can be found online at http://www.frontiersin.org/articles/10.3389/fsufs.2017.00002/ full\#supplementary-material.

Jordan-Meille, L., Rubæk, G. H., Ehlert, P. A. I., Genot, V., Hofman, G., Goulding, K. et al. (2012). An overview of fertilizer-P recommendations in Europe: soil testing, calibration and fertilizer recommendations. Soil Use Manag. 28, 419-435. doi:10.1111/j.1475-2743.2012.00453.x

Kouno, K., Tuchiya, Y., and Ando, T. (1995). Measurement of soil microbial biomass phosphorus by an anion-exchange membrane method. Soil Biol. Biochem. 27, 1353-1357. doi:10.1016/0038-0717(95)00057-L

Kuligowski, K., Poulsen, T. G., Rubæk, G. H., and Sørensen, P. (2010). Plantavailability to barley of phosphorus in ash from thermally treated animal manure in comparison to other manure based materials and commercial fertilizer. Eur. J. Agron. 33, 293-303. doi:10.1016/j.eja.2010.08.003

Li, X., Petersen, S. O., Sørensen, P., and Olesen, J. E. (2015). Effects of contrasting catch crops on nitrogen availability and nitrous oxide emissions in an organic cropping system. Agric. Ecosyst. Environ. 199, 382-393. doi:10.1016/J. Agee.2014.10.016

Li, X., Rubæk, G. H., and Sørensen, P. (2016). High plant availability of phosphorus and low availability of cadmium in four biomass combustion ashes. Sci. Total Environ. 557-558, 851-860. doi:10.1016/j.scitotenv.2016.03.077

Li, X., Rubæk, G. H., and Sørensen, P. (2017). Availability of potassium in biomass combustion ashes and gasification biochars after application to soils with variable pH and clay content. Arch. Agron. Soil Sci. doi:10.1080/03650340. 2017.1414198

Macdonald, L. M., Farrell, M., Van Zwieten, L., and Krull, E. S. (2014). Plant growth responses to biochar addition: an Australian soils perspective. Biol. Fert. Soils 50, 1035-1045. doi:10.1007/s00374-014-0921-Z

Morales, M. M., Comerford, N., Guerrini, I. A., Falcao, N. P. S., and Reeves, J. B. (2013). Sorption and desorption of phosphate on biochar and biochar-soil mixtures. Soil Use Manag. 29, 306-314. doi:10.1111/sum.12047

Mozaffari, M., Russelle, M. P., Rosen, C. J., and Nater, E. A. (2002). Nutrient supply and neutralizing value of alfalfa stem gasification ash. Soil Sci. Soc. Am. J. 66, 171-178. doi:10.2136/sssaj2002.1710

Müller-Stöver, D., Ahrenfeldt, J., Holm, J. K., Shalatet, S. G. S., Henriksen, U., and Hauggaard-Nielsen, H. (2012). Soil application of ash produced by lowtemperature fluidized bed gasification: effects on soil nutrient dynamics and crop response. Nutr. Cycl. Agroecosyst. 94, 193-207. doi:10.1007/s10705-012-9533-x

Murphy, P. N. C., and Stevens, R. J. (2010). Lime and gypsum as source measures to decrease phosphorus loss from soils to water. Water Air Soil Poll. 212, 101-111. doi:10.1007/s11270-010-0325-0

Olsen, S. R., Watanabe, F. S., Cosper, H. R., Larson, W. E., and Nelson, L. B. (1954). Residual phosphorus availability in long-time rotations on calcareous soils. Soil Sci. 78, 141-151. doi:10.1097/00010694-195408000-00008

Pan, H., and Eberhardt, T. L. (2011). Characterization of fly ash from the gasification of wood and assessment for its application as a soil amendment. BioResources 6, 3987-4004.

Parés-Viader, R., Jensen, P. E., Ottosen, L. M., Thomsen, T. P., Ahrenfeldt, J., and Hauggaard-Nielsen, H. (2016). "Comparison of phosphorus recovery from 
incineration and gasification sewage sludge ash," in 2nd IWA Conference on Holistic Sludge Management (HSM2016) (Malmö, Sweden).

R Core Team. (2015). R: A Language and Environment for Statistical Computing. Vienna, Austria: R Foundation for Statistical Computing. Available at: https:// www.R-project.org/

Rubæk, G. H. (2008). "Long-term effects of liming and phosphorus fertilisation on soil properties," in Long-term Field Experiments - A Unique Research Platform, Vol. 137, eds B. T. Christensen, J. Petersen, and M. Schacht (Aarhus: DJF Report Plant Science), 56-59.

Rubæk, G. H., Kristensen, K., Olesen, S. E., Østergaard, H. S., and Heckrath, G. (2013). Phosphorus accumulation and spatial distribution in agricultural soils in Denmark. Geoderma 209, 241-250. doi:10.1016/j.geoderma.2013.06.022

Schoenau, J. J., and Huang, W. Z. (1991). Anion-exchange membrane, water, and sodium-bicarbonate extractions as soil tests for phosphorus. Commun. Soil Sci. Plan. 22, 465-492. doi:10.1080/00103629109368432

Spokas, K. A., Cantrell, K. B., Novak, J. M., Archer, D. W., Ippolito, J. A., Collins, H. P., et al. (2012). Biochar: a synthesis of its agronomic impact beyond carbon sequestration. J. Environ. Qual. 41, 973-989. doi:10.2134/jeq2011.0069

Supancic, K., Obernberger, I., Kienzl, N., and Arich, A. (2014). Conversion and leaching characteristics of biomass ashes during outdoor storage - results of laboratory tests. Biomass Bioenergy 61, 211-226. doi:10.1016/j.biombioe.2013.12.014

Thomsen, T. P., Ravenni, G., Holm, J. K., Ahrenfeldt, J., Hauggaard-Nielsen, H., and Henriksen, U. B. (2015). Screening of various low-grade biomass materials for low temperature gasification: method development and application. Biomass Bioenergy 79, 128-144. doi:10.1016/j.biombioe.2014.12.019

Trippe, K. M., Griffith, S. M., Banowetz, G. M., and Whitaker, G. W. (2015). Changes in soil chemistry following wood and grass biochar amendments to an acidic agricultural production soil. Agron. J. 107, 1440-1446. doi:10.2134/agronj14.0593

Vassilev, S. V., Baxter, D., Andersen, L. K., and Vassileva, C. G. (2013). An overview of the composition and application of biomass ash. Part 2. Potential utilisation, technological and ecological advantages and challenges. Fuel 105, 19-39. doi:10.1016/j.fuel.2012.10.001

Wang, T., Camps-Arbestain, M., Hedley, M., and Bishop, P. (2012). Predicting phosphorus bioavailability from high-ash biochars. Plant Soil 357, 173-187. doi:10.1007/s11104-012-1131-9

Wang, Y., Lin, Y. X., Chiu, P. C., Imhoff, P. T., and Guo, M. X. (2015). Phosphorus release behaviors of poultry litter biochar as a soil amendment. Sci. Total Environ. 512, 454-463. doi:10.1016/j.scitotenv.2015.01.093

Weng, L. P., Vega, F. A., and Van Riemsdijk, W. H. (2011). Competitive and synergistic effects in $\mathrm{pH}$ dependent phosphate adsorption in soils: LCD modeling. Environ. Sci. Technol. 45, 8420-8428. doi:10.1021/es201844d

Xu, G., Sun, J. N., Shao, H. B., and Chang, S. X. (2014). Biochar had effects on phosphorus sorption and desorption in three soils with differing acidity. Ecol. Eng. 62, 54-60. doi:10.1016/j.ecoleng.2013.10.027

Zhai, L. M., Caiji, Z. M., Liu, J., Wang, H. Y., Ren, T. Z., Gai, X. P., et al. (2015). Short-term effects of maize residue biochar on phosphorus availability in two soils with different phosphorus sorption capacities. Biol. Fert. Soils 51, 113-122. doi:10.1007/s00374-014-0954-3

Conflict of Interest Statement: The authors declare that the research was conducted in the absence of any commercial or financial relationships that could be construed as a potential conflict of interest.

Copyright (C) 2017 Li, Rubck, Müller-Stöver, Thomsen, Ahrenfeldt and Sørensen. This is an open-access article distributed under the terms of the Creative Commons Attribution License (CC BY). The use, distribution or reproduction in other forums is permitted, provided the original author(s) or licensor are credited and that the original publication in this journal is cited, in accordance with accepted academic practice. No use, distribution or reproduction is permitted which does not comply with these terms. 